\title{
The GO model: A reconsideration of the role of structural units in guiding and organizing text on line
}

\author{
SETH N. GREENBERG \\ Union College, Schenectady, New York \\ ALICE F. HEALY \\ University of Colorado, Boulder, Colorado \\ and \\ ASHER KORIAT and HAMUTAL KREINER \\ University of Haifa, Haifa, Israel
}

\begin{abstract}
Healy (1994) and Koriat and Greenberg (1994) offered different theoretical accounts of the missingletter effect (MLE) in the letter-detection task, whereby a disproportionate number of letter-detection errors occur in frequent function words. Healy emphasized identification processes, whereas Koriat and Greenberg viewed the structural role of the embedding word to be crucial. Recent research suggests that neither position alone can account for the complete set of observations pertaining to the MLE. The present paper offers a theoretical integration of these competing explanations of letter detection in terms of a GO (guidance-organization) model of reading. This model specifies how structural processing of connected text helps guide eye movements to semantically informative parts of the text, enabling readers to achieve on-line fluency.
\end{abstract}

In separate, adjacent reviews, Healy (1994) and Koriat and Greenberg (1994) summarized their opposing theoretical positions concerning the processes responsible for the missing-letter effect (MLE). This robust effect refers to the finding that letter detection in connected text is more difficult in frequent function words such as the than in less common words. According to Healy's unitization approach, the MLE discloses the reader's reliance on familiarity in processing text in terms of supraletter units such as syllables, words, or even short phrases. The assumption is that text analysis is a hierarchic process wherein smaller units such as letters, syllables, and even words are processed within the higher order units in which they are embedded. Once a unit at a certain level is identified, readers proceed to the next segment of text without completing the processing of lower level units such as constituent letters. Hence letters are missed most often when they appear in very familiar, unitized words or phrases. In contrast, according to Koriat and Greenberg, the MLE reflects

Part of the present work was completed when the first author was on sabbatical leave at University of Colorado at Boulder. This work was supported in part by an NSF-ROA grant to S.N.G. under Grant NSF9810169 awarded to Albrecht Inhoff. This research was also supported in part by Army Research Institute Contracts DASW01-99-K0002 and DASW01-03-K-0002 to the University of Colorado (A.F.H., principal investigator). Correspondence concerning this article should be sent to S. N. Greenberg, Department of Psychology, Union College, Schenectady, NY 12308 (e-mail: greenbes@union.edu). the role of function words as cues for sentence structure (Kimball, 1973). By their structural precedence view, the on-line analysis of text requires the encoding of both structure and meaning, but the processing of structure leads the way to the processing of meaning. Early in text processing, readers monitor text for function morphemes and use them as cues to establish a structural frame into which incoming information can be assimilated. Subsequently, structural cues recede to the background as attention shifts from structure to content. Hence letters are missed most often in function morphemes used to establish a structural frame.

Whereas Healy's (1994) account led to an emphasis on frequency and familiarity, Koriat and Greenberg's (1994) position stressed the structural role of words and morphemes, and the context that determines this role. Both views, however, share the idea that the MLE derives from the hierarchical nature of text processing.

As evidence mounted, it became increasingly apparent that both views must be combined to account for all the results that have been accumulated. The present paper offers a new model, the guidance-organization (GO) model of reading, which provides a theoretical integration of these two competing views. According to this model, unitization processes facilitate the identification of function words that can serve as cues for the structural organization of the sentence. This organization then guides attention to content words and enables on-line semantic analysis and integration. The GO model, then, is an account of how read- 
ers coordinate text elements to achieve on-line integration when reading text.

\section{Structural Analysis During Reading: A Role for the Function Words}

The assimilation of each text segment into a gradually evolving coherent schema requires a balance between sequential encoding of independent orthographic units and a more global encoding of the structural organization of these units within the schema. Reading can thus be seen to recapitulate the processes underlying speech production, whereby structure is established early and slots within this structure are then filled by their appropriate units (Bock, 1990). For example, readers are successful in assigning natural prosody to unfamiliar text immediately upon its reading. Furthermore, the prosodic patterns applied are tuned to the structure of the text and are largely indifferent to sentence content (Koriat, Greenberg, \& Kreiner, 2002). These results, along with findings on speech production in which prosodic timing patterns roughly match sentence syntactic structure (Ferreira, 1993), suggest the precedence of structure over meaning in reading.

At an early stage in text processing, readers strive to establish a tentative frame for the entire sentence, so that sequentially accessed units can be assimilated into an evolving structural schema (Aaronson \& Ferres, 1983). The extraction of a structural frame is assumed to depend on a fast and shallow analysis of cues that disclose the structure. Once established, the frame helps organize and maintain the serially encoded information in working memory, while integrating it with succeeding components of text (Just \& Carpenter, 1987). The analysis of structure leads the way to the analysis of meaning so that the interpretation of each reading unit can be subordinated on line to the interpretation of the encompassing unit rather than be delayed until the entire sentence has been read. This proposal is consistent with sentence comprehension models (Perfetti, 1989) suggesting that the syntactic analysis performed on line is independent of semantic and pragmatic considerations.

How do readers extract phrase structure independently of, and prior to, the analysis of content during reading? Function words generally indicate that a new syntactic unit is being introduced (Kimball, 1973). Furthermore, readers use closed class words such as prepositions, articles, conjunctions, and clausal adverbs as forerunners that signal syntactic parsing and prepare the groundwork for meaning identification and integration (Perfetti, 1985). The unitization model stresses the perceptual properties of these forerunners as facilitating their identification particularly in the parafoveal region (Hadley \& Healy, 1991). The GO model assumes that these perceptual properties permit the reader to locate forerunners by parafoveal processing, so that they can be utilized relatively early to signal the structure of the phrase and guide the eyes to the ensuing meaning units. Support for distinctive processing of function words has emerged from neuropsychological research (e.g., Mohr, Pulvermüller, \& Zaidel, 1994).

\section{Processing Function Units During Reading: Evidence from the MLE}

We take as our point of departure the extensive work on letter detection. Admittedly, the letter-detection task is somewhat compromised by a divided effort between letter detection and reading. However, this line of research provides a useful and extensive look at on-line use of structural markers. In particular, we focus on the MLE, whereby letter-detection errors occur disproportionately on frequent function words. This effect might be attributed to readers simply ignoring such words (Corcoran, 1966; Haber \& Schindler, 1981). However, both the unitization and structural models assume that processing of function words clearly takes place. The distinction between the models concerns the stage at which the processing of function words leads to letter-detection errors. The structural model attributes letter-detection failure to postlexical assignment of a role to the function words, whereas the unitization account considers the perceptual familiarity of the orthographic pattern of most function words to be critical and thus posits the effect to be in the prelexical or lexical stage. The GO model continues to emphasize function word processing in an effort to explain on-line integration, but it does so by meshing the ease of identification with the ready employment of function words as structural placeholders.

Many studies suggest that the MLE is sensitive to the structural role of the word within the sentence. Specifically, when Hebrew letters functioned as structural prefixes (e.g., prepositions, conjunctions, or determiners) appended to content words they engendered more errors than when they were the initial letters in a content stem (Koriat, Greenberg, \& Goldshmid, 1991), even when homographic strings were used. Also, constituent target letters were more difficult to detect when appearing in nonwords that replaced function words as compared with those that replaced content words (Koriat \& Greenberg, 1991). In addition, letter detection in the prepositions on and in was more difficult when in a function (on her way/ in her bedroom) as compared with a content (on switch/in crowd) role (Greenberg \& Koriat, 1991; Moravcsik \& Healy, 1995). Likewise, there were fewer letter-detection errors on the when it was used as an adverb (feel the better for it) than as a definite article (from the family) (Moravcsik \& Healy, 1998). Further, letter detection in content morphemes that immediately followed functors (detecting $c$ in the cat) was superior relative to content morphemes positioned elsewhere (detecting $c$ in thin cat) (Koriat \& Greenberg, 1996). Together, these various effects suggest an on-line figure-ground representation of text in which structural elements recede to the background as the content elements that they introduce are pushed to the foreground.

The structural approach assumes that functors are monitored on the basis of a shallow and rapid initial analysis of text, but it does not provide a mechanism by which such fast-paced monitoring takes place. Such a mechanism, however, is suggested by the unitization model. According to 
this model, although readers process text in parallel at several levels of analysis (e.g., letter, syllable, word, and phrase), familiarity with a unit at a given level permits fast access to its unitized representation, preempting access to lower level representations. Highly familiar words tend to activate their unitized representations at the whole-word level before the processing of their constituent letters has been completed. Thus, the MLE is attributed to unitization of short, high-frequency function words and is symptomatic of the processing of units larger than the letter.

Several findings demonstrate the contribution of orthographic familiarity to the MLE. In particular, the MLE occurs even in scrambled text (i.e., words presented in random order; Healy, 1976), suggesting that it does not depend solely on the word's role within the sentence. The size of the processing unit in reading depends on the familiarity of the word's visual configuration: For example, readers make a significantly higher proportion of detection errors in relatively common than in relatively rare content words both in word lists (Healy, 1976) and in connected text (Greenberg, Koriat, \& Vellutino, 1998). The frequency of pronouns further affects the rate of letter-detection errors (Moravcsik \& Healy, 1995).

Orthographic variations that destroy the familiar visual shape of a common word reduce the magnitude of the MLE. Type case alternation was found to reduce letter-detection errors substantially, particularly in high-frequency function words (Drewnowski \& Healy, 1977). In addition, introducing misspellings in familiar words reduced letterdetection errors (Healy \& Drewnowski, 1983; Healy, Fendrich, \& Proctor, 1990). Inserting asterisks or blank spaces between letters also reduced the magnitude of the MLE (Healy, Conboy, \& Drewnowski, 1987). Further, less familiar text fonts reduced the size of the MLE (Schneider \& Healy, 1993). Finally, compelling evidence was provided for the role of word shape in word recognition using a proofreading paradigm (Healy \& Cunningham, 1992). Together, these results suggest that orthographic variations that impair the global shape of a common word improve letter detection by inhibiting whole-word access.

Several studies addressed the effects of context on the MLE. First, the MLE occurred when readers processed a string of words, but not when they processed words in isolation (Healy, Oliver, \& McNamara, 1987); without a string of words available, the readers were not compelled to move rapidly beyond the function word. Second, with different-sized slits in index cards that served as viewing windows exposing different amounts of text, the MLE occurred only when the slit was large enough to expose a wide portion of the text (Hadley \& Healy, 1991).

Moravcsik and Healy $(1995,1998)$ showed that familiarity of both word meaning and structural usage influences letter detection. To account for these and earlier findings, they proposed the processing-time hypothesis, which states that the more time spent processing a word, whether because of its unfamiliar configuration, structural role, or meaning, the greater the likelihood that its individual letters will be identified. Although the unitization model thereby incorporates a mechanism to cope with the influence of semantic and syntactic factors on letter detection, this model does not specify the particular semantic and syntactic processes involved.

Thus, neither the structural nor the unitization account alone can fully explain the pattern of letter-detection errors. In particular, when either role differences are eliminated (Moravcsik \& Healy, 1995) or perceptual integrity is destroyed (Drewnowski \& Healy, 1977), the MLE still survives. Apparently, both perceptual analysis and structural role contribute to the MLE. Consequently, we propose a model that incorporates ideas from both positions within a unifying framework. This framework creates a more comprehensive understanding of the reading process that generates testable predictions for eye movements as well as for letter detection. The first two assumptions derive from the unitization model, whereas the last two assumptions reflect the structural account. The middle assumption stresses a collaborative interaction between bottom-up and top-down processes.

\section{The GO Model: The Role of Function Words in On-line Guidance and Organization of Text Processing}

The GO model makes the following five assumptions, progressing from bottom-up to top-down processes:

Unitization assumption. Quick identification of structure-supporting function units is aided by their relative orthographic familiarity. Because of their high familiarity, such units can contact their whole-word unitized representations before the analysis of their constituent letters is completed. Therefore, orthographic variations that disrupt their global visual shape impair their ability to serve as forerunners for text processing. The time spent processing high-frequency function words at the whole-word level is relatively short, thereby enabling the fast and early use of these words to build a tentative structural frame. Some high-frequency content words are also likely to enjoy fast whole-word identification, but because of contextual constraints, they are less likely to serve as forerunners in structure building.

Parafoveal processing assumption. The whole-word identification of function words is normally achieved when they are in the parafovea, where visual acuity is too low to afford letter-by-letter analysis but can still support fast access to whole-word unitized representations. Utilization of the structural information conveyed by these items may also begin while they are in the parafovea. As noted, letter detection depends not only on whether the is embedded in continuous text, but also on whether it is first encountered in the parafovea (Hadley \& Healy, 1991). In concert with some more expansive reading models (e.g., EZ reader; Reichle, Pollatsek, Fisher, \& Rayner, 1998), parafoveal analysis of function units helps adjust or repair the planned pattern of eye movement from the fovea, word $n$, over a function word to a more meaning-laden unit, word $n+2$.

Contextual constraint assumption. Identification of function words as potential forerunners in the parafovea is also aided by their high predictability in text. Contextual 
constraints are critical in helping to identify sentential slots where structure-supporting units are likely to reside. Such constraints operate in a top-down manner to assess whether a parafoveal pattern is signaling the start of a new unit. In addition, following MacDonald, Pearlmutter, and Seidenberg (1994), layers of syntactic and semantic patterns may derive from the frequency in which ambiguous target units appear in various sentence contexts. Orthographic patterns engender different letter-detection patterns based on usage, presumably because of contextual constraints. These constraints are responsible for (1) inhibiting the use of quickly identified high-frequency content or function words as structural forerunners when they do not support structure, (2) facilitating the identification of structure-supporting prefixes (as in Hebrew) or suffixes (e.g., -ing; Drewnowski \& Healy, 1980) and their parsing when the word is still in the parafovea, and (3) utilizing relatively unfamiliar units (e.g., nonwords or misspelled functors) in a structure-supporting capacity when they occupy a function slot in a sentence. Ambiguity exists in much of lexical identification, if not at the lexical level often at the syntactic or discourse level (MacDonald et al., 1994). However, function words disproportionately favor one usage over another and, hence, unless strong counter interpretations are supported, initial resolution will reliably signify a structural usage.

Structural precedence assumption. The early extraction of sentence structure is essential to the on-line processing of text. Although a full articulation of structure proceeds in parallel with semantic analysis, critical structural divisions are generally construed in advance of full semantic analysis and possibly independently of it.

Guidance assumption. The parafoveal identification of function units provides structural cues that help the reader rapidly discover the organization of the text. Incremental updating of structural information enhances the readers' focus on meaning-laden units and aids their online assimilation into an integrated semantic representation. Thus, structure can be established along with the analysis of meaning units. Eye movements, then, represent the output of a structure-defining process that is designed to allocate focal attention to meaning-laden elements in text. Much, though not all, of eye movement occurs through a "dumb" mechanism (Reichle et al., 1998). Specifically, unless context cues afford an exceptional interpretation, function word patterns are reliable markers of structural boundaries that foment more than their share of short gazes or word skips in the direction of more meaningful units.

\section{The GO Model: A Brief Consideration of Implications for Eye Movements}

Researchers have increasingly embraced eye-movement methodology as a window to on-line text processing. The primary dependent measures include saccade length, fixation duration (including first fixation and total gaze time), and regressions (Rayner \& Pollatsek, 1989). More recent work has also used skip rate, landing posi- tion, and "spillover" effects to examine cognitive processes underlying skilled reading (Reichle et al., 1998). Although there has been a great deal of work on the effects of perceptual and lexical variables on eye movement (Rayner \& Pollatsek, 1989), until recently few studies have systematically considered how structural markers might guide such movements.

Perhaps the most suggestive eye-movement findings are those that have examined skipping rates of content and function words. Eye-movement results indicate that about $80 \%$ of content words are fixated, as opposed to only $20 \%$ of function words (Carpenter \& Just, 1983; Reichle et al., 1998). Carpenter and Just noted that although frequent short words were most likely to be skipped, three-letter function words (e.g., the) were more prone to being skipped than three-letter content words (e.g., run). Schmauder, Morris, and Poynor (2000), though, found little evidence of function-word skipping, possibly because they used moderately long function words (5.2 letters on average) that could discourage skipping (Brysbaert \& Vitu, 1998). However, O'Regan (1979) and Gautier, O'Regan, and Le Gargasson (2000) observed that the initial saccades toward parafoveally placed targets are 1.5 letters farther to the right for function than for content words matched on length. When longer function and content words are targets of interest (Schmauder et al., 2000), differences might be apparent in landing positions rather than skips.

According to the GO model, the high rate of skipping function words reflects the regulation of eye movements by structure-defining processes. Unitization provides a mechanism by which very familiar function words can be processed while they are still in the parafovea, implying that part of the MLE for function words is mediated by eye-movement patterns. Greenberg, Inhoff, and Koriat (2004) examined the processing of three-letter function and content words when readers were allowed to preview three words to the right of a fixated word or denied preview. Readers pressed a button whenever they detected a $t$. Although skipping three-letter content words was not affected by preview, skipping the markedly increased under preview. Detection of $t$ in the was most adversely affected by preview. The frequency of the content words was inconsequential, suggesting that skipping is affected by whether or not an easily identified word serves as a potential structural forerunner. Indeed, Saint-Aubin and Klein (2001) found that impeding parafoveal processing generally decreased omission rates for function but not content words. However, letters in function words were missed more often than in content words for both fixated and skipped words, suggesting that skipping does not tell the whole story.

With regard to contextual information, O'Regan (1979) found longer eye movements approaching the than approaching three-letter content words, even with prior sentence context controlled. Moreover, the magnitude of the the-skipping effect was influenced by manipulations that varied sentence structure. Balota, Pollatsek, and Rayner (1985) found that contextually predictable words were skipped more than visually matched less predictable words, 
and that parafoveal preview more greatly aided the processing of predictable words. Many studies have revealed more complex semantic and syntactic contextual effects on eye movements, but these studies did not focus specifically on structural extraction (e.g., Rayner, Raney, \& Pollatsek, 1995). They indicate that context affects eyemovement measures other than skip rate, implying that extraction of structural boundaries can drive eye-movement patterns. It reasonably follows that structural markers communicating such boundaries will play a potent role in regulating those patterns.

Although eye-movement research has yielded mixed evidence (e.g., Inhoff, 1989), on balance there is a good indication that morphological determination can occur during parafoveal preview, thereby permitting readers to respond to structural morphemes even when these are embedded in complex words. Inhoff, Briihl, and Schwartz (1996) showed that compound words drew longer fixations than did equally long monomorphemic words, suggesting that morphological parsing beginning in the parafovea may increase fixation time. Further, initial landing position was nearer the center of compound words than of the monomorphemic words. Hyönä and Pollatsek (1998) found a slight effect on landing position of the frequency of the initial morpheme. Deutsch, Frost, Pollatsek, and Rayner (2000) have provided further support for early morphological extraction with Hebrew. When a parafoveal prime consisted of the root morpheme, it facilitated target naming more than did other primes that shared the same number of letters with the target. Likewise, Farrid and Grainger (1996) found that initial landings in Arabic were altered when the root word was prefixed or suffixed.

With respect to the GO model's contentions regarding the interplay of lexical identification and postlexical processes on different word classes, Schmauder et al. (2000) obtained a strong effect of word frequency on the initial processing of both function and content words. The measures of first-fixation and gaze durations, both of which are presumed to indicate lexical identification or front-end processing, were longer for less frequent words regardless of word class. However, the measures of text integration and reanalysis indicated differences between function and content word processing. Furthermore, processing times on content words immediately following function words were greater than on such words following content words.

In sum, the eye-movement literature offers findings consistent with the GO model's assumptions. These findings suggest that it is possible not only to extract cues to structure during parafoveal processing of words, but also to identify embedded structure-defining prefixes. Thus, both letter-detection work and these eye-movement findings point toward the more comprehensive and integrated approach taken by the GO model. Importantly, this model articulates a constellation of assumptions that provide a reasonable mechanism for the reader's on-line acquisition of structure and specifics with regard to how simple structural units are obtained through the function word/morpheme guidance of eye movements. It remains to be seen, though, whether this model's assumptions, derived from the letter-detection literature, gain support with more decisive and exacting tests of the specific influence of structuresupport units on eye-movement patterns during reading.

\section{REFERENCES}

Aaronson, D., \& Ferres, S. (1983). Lexical categories and reading tasks. Journal of Experimental Psychology: Human Perception \& Performance, 9, 675-699.

Balota, D. A.., Pollatsek, A., \& Rayner, K. (1985). The interaction of contextual constraints and parafoveal visual information in reading. Cognitive Psychology, 17, 364-390.

BocK, K. (1990). Structure in language: Creating form in talk. American Psychologist, 45, 1221-1236.

BRYSBAERT, M., \& VITU, F. (1998). Word skipping: Implications for theories of eye movement control in reading. In G. Underwood (Ed.), Eye guidance in reading and scene perception (pp. 125-147). Oxford: Elsevier.

Carpenter, P. A., \& Just, M. A. (1983). What your eyes do while your mind is reading. In K. Rayner (Ed.), Eye movements in reading: Perceptual and language processes (pp. 275-307). New York: Academic Press.

Corcoran, D. W. J. (1966). An acoustic factor in letter cancellation. Nature, $210,658$.

Deutsch, A., Frost, R., Pollatsek, A., \& Rayner, K. (2000). Early morphological effects in word recognition in Hebrew: Evidence from parafoveal preview benefit. Language \& Cognitive Processes, $\mathbf{1 5}$, 487-506.

DREWNOWSKI, A., \& HeAly, A. F. (1977). Detection errors on the and and: Evidence for reading units larger than the word. Memory \& $\mathrm{Cog}$ nition, 5, 636-647.

DrewnowsKi, A., \& HeAly, A. F. (1980). Missing -ing in reading: Letter detection errors in word endings. Journal of Verbal Learning \& Verbal Behavior, 19, 247-262.

FARRID, M., \& GRAINGER, J. (1996). How initial fixation position influences visual word recognition: A comparison of French and Arabic. Brain \& Language, 53, 351-368.

FERREIRA, F. (1993). Creation of prosody during sentence production. Psychological Review, 100, 233-253.

Gautier, V., O'Regan, K. J., \& Le Gargasson, J. F. (2000). "Theskipping" revisited in French: Programming saccades to skip the article "les." Vision Research, 40, 2517-2531.

GreEnberG, S. N., INHOFF, A. W., \& Koriat, A. (2004). Eye movements in response to frequency and function. Manuscript in preparation.

GreenberG, S. N., \& Koriat, A. (1991). The missing-letter effect for common function words depends on their linguistic function in the phrase. Journal of Experimental Psychology: Learning, Memory, \& Cognition, 17, 1051-1061.

GreenberG, S. N., Koriat, A., \& Vellutino, F. R. (1998). Age changes in the missing-letter effect reflect the reader's growing ability to extract structure from text. Journal of Experimental Child Psychology, 69, 175-198.

HABER, R. N., \& SCHINDLER, R. M. (1981). Error in proofreading: Evidence of syntactic control of letter processing? Journal of Experimental Psychology: Human Perception \& Performance, 7, 573-579.

HaDLEY, J. A., \& Healy, A. F. (1991). When are reading units larger than the letter? Refinement of the unitization reading model. Journal of Experimental Psychology: Learning, Memory, \& Cognition, 17, 1062-1073.

HEALY, A. F. (1976). Detection errors on the word the: Evidence for reading units larger than letters. Journal of Experimental Psychology: Human Perception \& Performance, 2, 235-242.

HEALY, A. F. (1994). Letter detection: A window to unitization and other cognitive processes in reading text. Psychonomic Bulletin \& Review, 1, 333-344.

HeAly, A. F., Conboy, G. L., \& Drewnowski, A. (1987). Characterizing the processing units of reading: Effects of intra- and interword spaces in a letter detection task. In B. K. Britton \& S. M. Glynn (Eds.), 
Psychology of reading and reading instruction (pp. 279-296). Hillsdale, NJ: Erlbaum.

Healy, A. F., \& Cunningham, T. F. (1992). A developmental evaluation of the role of word shape in word recognition. Memory \& Cognition, 20, 141-150.

HEALY, A. F., \& DREWNOWSKI, A. (1983). Investigating the boundaries of reading units: Letter detection in misspelled words. Journal of Experimental Psychology: Human Perception \& Performance, 9, 413426.

Healy, A. F., Fendrich, D. W., \& Proctor, J. D. (1990). Acquisition and retention of a letter-detection skill. Journal of Experimental Psychology: Learning, Memory, \& Cognition, 16, 270-281.

HeAly, A. F., Oliver, W. L., \& McNamara, T. P. (1987). Detecting letters in continuous text: Effects of display size. Journal of Experimental Psychology: Human Perception \& Performance, 13, 279-290.

HYöNÄ, J., \& PollatSEK, A. (1998). Reading Finnish compound words: Eye fixations are affected by component morphemes. Journal of Experimental Psychology: Human Perception \& Performance, 24, 16121627.

INHOFF, A. W. (1989). Lexical access during eye fixations in reading: Are word access codes used to integrate lexical information across interword fixations? Journal of Memory \& Language, 28, 444-461.

InHofF, A. W., BRIIHL, D., \& SCHWARTZ, J. (1996). Compound word effects differ in reading, on-line naming, and delayed naming tasks. Memory \& Cognition, 24, 466-476.

JuST, M. A., \& CARPENTER, P. A. (1987). The psychology of reading and language comprehension. Needham Heights, MA: Allyn \& Bacon.

KimbaLL, J. (1973). Seven principles of surface structure parsing in natural language. Cognition, 2, 15-47.

Koriat, A., \& GREenBERG, S. N. (1991). Syntactic control of letter detection: Evidence from English and Hebrew nonwords. Journal of Experimental Psychology: Learning, Memory, \& Cognition, 17, $1035-$ 1050 .

Koriat, A., \& Greenberg, S. N. (1994). The extraction of phrase structure during reading: Evidence from letter detection errors. Psychonomic Bulletin \& Review, 1, 345-356.

KORIAT, A., \& GREENBERG, S. N. (1996). The enhancement effect in letter detection: Further evidence for the structural model of reading. Journal of Experimental Psychology: Learning, Memory, \& Cognition, 22, 1184-1195.

Koriat, A., GreenberG, S. N., \& Goldshmid, Y. (1991). The missingletter effect in Hebrew: Word frequency or word function? Journal of Experimental Psychology: Learning, Memory, \& Cognition, 17, 66-80.

Koriat, A., Greenberg, S. N., \& Kreiner, H. (2002). The extraction of structure during reading: Evidence from reading prosody. Memory \& Cognition, 30, 270-280.

MacDonald, M.C., Pearlmutter, N. J., \& Seidenberg, M. S. (1994). The lexical nature of syntactic ambiguity resolution. Psychological Review, 101, 676-703.

Mohr, B., Pulvermüller, F., \& Zaidel, E. (1994). Lexical decision after left, right and bilateral presentation of function words, content words and non-words: Evidence for interhemispheric interaction. Neuropsychologia, 32, 105-124.

MorAvCSIK, J. E., \& HEALY, A. F. (1995). The effect of meaning on letter detection. Journal of Experimental Psychology: Learning, Memory, \& Cognition, 21, 82-95.

MoravcsiK, J. E., \& Healy, A. F. (1998). Effect of syntactic role and syntactic prominence on letter detection. Psychonomic Bulletin \& Review, 5, 96-100.

O'REGAN, K. (1979). Saccade size control in reading: Evidence for the linguistic control hypothesis. Perception \& Psychophysics, 25, 501509.

Perfetti, C. A. (1985). Reading ability. New York: Oxford University Press.

Perfetti, C. A. (1989). There are generalized abilities and one of them is reading. In L. B. Resnick (Ed.), Knowing, learning and instruction: Essays in honor of Robert Glaser (pp. 307-335). Hillsdale, NJ: Erlbaum.

Rayner, K., \& Pollatsek, A. (1989). The psychology of reading. Englewood Cliffs, NJ: Prentice-Hall.

Rayner, K., Raney, G. E., \& Pollatsek, A. (1995). Eye movements and discourse processing. In R. F. Lorch, Jr. \& E. J. O'Brien (Eds.), Sources of coherence in reading (pp. 9-35). Hillsdale, NJ: Erlbaum.

Reichle, E. D., Pollatsek, A., Fisher, D. L., \& Rayner, K. (1998). Toward a model of eye movement control in reading. Psychological Review, 105, 125-157.

SAINT-AUBIN, J., \& KLEIN, R. M. (2001). Influence of parafoveal processing on the missing-letter effect. Journal of Experimental Psychology: Human Perception \& Performance, 27, 318-334.

SCHMAuder, A. R., Morris, R. K., \& Poynor, D. V. (2000). Lexical processing and text integration of function and content words: Evidence from priming and eye fixations. Memory \& Cognition, $\underline{\mathbf{2 8}}$, 1098-1108.

SchneIDER, V. I., \& Healy, A. F. (1993). Detecting phonemes and letters in text: Interactions between different types and levels of processes. Memory \& Cognition, 21, 739-751.

(Manuscript received January 15, 2003; revision accepted for publication June 30, 2003.) 